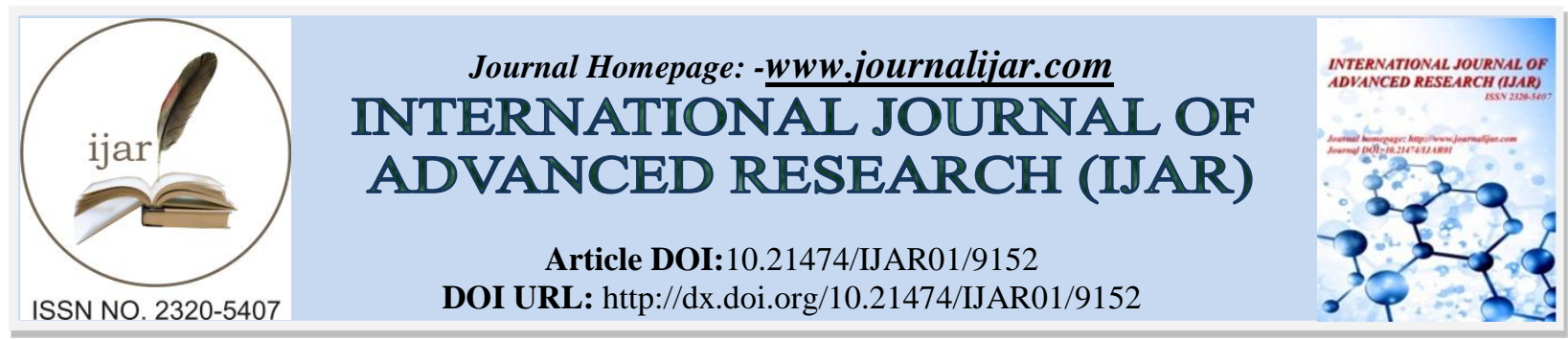

RESEARCH ARTICLE

\title{
ADULT AND PEDIATRIC MULTIPLE SCLEROSIS: DIFFERENCES AND SIMILARITIES.
}

\author{
Mohamed Gomaa, Hossam Egila, Abdulhakim Mohammad, Ashraf El-Mitwalli and Mohamed El-Khateeb. \\ Mansoura neurology department, Egypt.
}

\section{Manuscript Info}

Manuscript History

Received: 24 March 2019

Final Accepted: 26 April 2019

Published: May 2019

\begin{abstract}
Background: Multiple sclerosis (MS) can occur in pediatric age group with prevalence rates ranging from $2.2 \%-4.4 \%$ of all MS cases. This research conducted to compare adult multiple sclerosis with pediatric multiple sclerosis clinically and radiologically and to assess similarities and differences between them.

Methods: 30 MS patients divided into 2 groups (Group A aged 18 years or more at first presentation, group $\mathrm{B}$ less than 18 years) underwent detailed history taking, general , neurological examination, MRI brain for location and number of lesions and disability assessment using Expanded Disability Status Scale.

Results: No significant difference between the two groups as regard duration of first attack, frequency between monosymptomatic to polysymptomatic and complete to partial to no improvement from first attack and percentage of frequency of each of all MRI locations.

Conclusion: Pediatric and adult MS are similar as regard presentation ,progression and localization.
\end{abstract}

Copy Right, IJAR, 2019,. All rights reserved.

\section{Introduction:-}

Multiple sclerosis (MS) is a multifocal central nervous system (CNS) disorder characterised by inflammatory demyelinating lesions affecting white and grey matter; thought to be mediated by autoreactive $\mathrm{T}$ cells (Weiner, 2008).

Multiple sclerosis affects approximately 400,000 people in the United States and 2.5 million worldwide. More than 200 people are diagnosed with MS each week in the United States. MS typically begins between the ages of 20 and 40 years and it is the leading cause of non- traumatic disability in young adults (Tullman, 2013).

Multiple sclerosis is primarily disease of young adults, but can occur in pediatric age group. Several studies report prevalence rates of pediatric onset MS ranging from 2.2\%-4.4\% of all MS cases (Renoux et al., 2007), while some MS centers reported that up to $10 \%$ of their patients with MS experienced symptom onset prior to age 18 years (Ferreira et al., 2008).

Multiple sclerosis is a challenging diagnosis in children especially in young children, because of the atypical clinical, biological, and MRI presentations and the broader spectrum of potential differential diagnosis specific to that age range (Waubant\&Chabas, 2009).

Corresponding Author:-Mohamed Gomaa.

Address:-Mansoura neurology department, Egypt. 
So we conducted this research is to compare adult multiple sclerosis with pediatric multiple sclerosis clinically and radiologically and to assess similarities and differences between them.

\section{Patients}

The study was conducted on thirty patients whom divided into two groups: Adult MS group: It includes 15 patients aged 18 years or more at first presentation, met the diagnostic criteria for adult MS And Pediatric MS group: It includes 15 patients aged less than 18 years at first presentation, met the diagnostic criteria for pediatric MS with maximal age at interview of 25 years.

\section{Inclusion criteria}

For adult patients:

Patients fulfilled revised McDonald's criteria 2010 for diagnosis of multiple sclerosis.

\section{For pediatric patients:}

1. In patients aged 11 years or older and without ADEM presentations, they fulfilled revised McDonald's criteria 2010 for adult MS patients.

2. In patients aged less than 11 years or those with ADEM presentation, they fulfilled International Pediatric Multiple Sclerosis Study Group IPMSSG 2012 updated criteria for pediatric multiple sclerosis (Table-1).

\section{Exclusion criteria}

Radiologically isolated syndrome, clinically isolated syndrome,

Presence of neurological or medical condition(s) that explain the clinical and radiological picture of the patient other than MS and Pediatric patients of age more than 25 years at time of the study.

\section{Methods:-}

1. Detailed history taking, general and neurological examination to obtain the following: Clinical diagnosis by demonstration of dissemination in time and space, Exclusion of other diagnoses, Evaluation of any associated conditions, Demographic data and family history, Number, type and duration of first presenting symptom(s) and the improvement from it/them and Time between first and second attack, relapse rate, course type and duration of the disease.

2. Disability assessment using Expanded Disability Status Scale (EDSS)

3. Radiological assessment using MRI Brain, Cervical and Dorsal spine T1,T2 and Flair to confirm diagnosis, exclude other causes, estimate number and sites of MS plaques

\section{Results:-}

The study was conducted on 30 patients with mean age of adult group was $35.7 \pm 7.2$ years and the mean age of pediatric group was $18.4 \pm 4.5$ years. There was no significant difference between adult and pediatric groups as regard percentage of frequency of male to female (P-value > 0.05). Table (2)

The mean age at onset of adult group was $29.5 \pm 5.54$ years whereas in pediatric group was $14.3 \pm 2.92$ years. Time between first and second attack was found to be significantly higher in adult group when compared to pediatric group (P-values < 0.05) whereas there was no significant difference between adult and pediatric groups as regard of duration of first attack (P-value $>0.05$ ). There was no significant difference between adult and pediatric groups as regard percentage of frequency between each of; mono symptomatic to polysymptomatic and complete to partial to no improvement from first attack (both P-values >0.05). Table (3)

There was no significant difference between adult and pediatric groups as regard percentage of frequency of all types of symptoms of first attack (all P-values >0.05). Table (4)

There was no significant difference between adult and pediatric groups as regard EDSS scores and percentage of frequency of low disability to high disability (both P-values > 0.05). Table (5)

There was a significant positive association between each of disease duration and secondary progressive versus relapsing remitting course as reference category and EDSS as an outcome in adult group (both P- values < 0.05). There was no significant association between each of age, male gender, age of onset, relapse rate, polysymptomatic 
presentation versus mono symptomatic as reference category and incomplete improvement from first attack versus complete improvement as reference category and EDSS as an outcome in adult group (all P-values >0.05).

There was a significant positive association between each of incomplete improvement from first attack versus complete improvement as reference category and secondary progressive versus relapsing remitting course as reference category and EDSS as an outcome in pediatric group (both P-values < 0.05). There was no significant association between each of age, male gender, age of onset, disease duration, relapse rate and polysymptomatic presentation versus mono symptomatic as reference category and EDSS as an outcome in pediatric group (all Pvalues $>0.05)$. Table (6)

There was no significant difference between adult and pediatric groups as regard percentage of frequency of each of all MRI locations (all P-values > 0.05). About spinal cord lesions, all of them had cervical region involvement, while $25 \%$ of adults ( $13.3 \%$ of all cases) and $20 \%$ of pediatric cases ( $6.7 \%$ of all cases) had dorsal involvement. One adult patient (6.7\%) had tumefactive MS (large lesion $>2 \mathrm{~cm}$ ). Table (7)

\section{Discussion:-}

Multiple sclerosis (MS) is the most important immune-mediated demyelinated disease of human which is typically the disease of young adults. About $2.7 \%$ to $10.5 \%$ of patients have been reported to develop their first symptoms before their 18th birthday. About $80 \%$ of the pediatric cases and nearly all adolescent onset patients present with attacks typical to adult MS. Approximately $97 \%$ to $99 \%$ of the affected children have relapsing-remitting MS, while $85 \%$ to $95 \%$ of the adults experience such condition. MS in children is associated with more frequent and severe relapses (Inaloo \& Haghbin, 2013).

This study included 15 adult patients and 15 pediatric patients. The mean age of adult patients was 35.72 years ranging from 21 to 49 years and mean age of pediatric patients was 18.4 years ranging from 10 to 25 years. This was matched with Benson et al., (2014) about adult group but mismatched about pediatric group which was (15.6 \pm 2.8$)$ because of difference of age criteria that they excluded patients of age above 19 years at time of study and we excluded patients of age above 25 years at study time.

The mean age of onset was 29.47 years for adult group ranged from 20 to 38 years and 14.33 years for pediatric group ranging from 9 to 17.75 years. These results are in agreement with Chong and Benjamin (2007), and Benson et al. (2014) for both adult and pediatric MS patients and Renouxet al. (2007), and Ekmekci et al. (2012), for pediatric MS patients.

First presentation was polysymptomatic in $46.7 \%$ of adult patients and $60 \%$ of pediatric patients in our study which is insignificantly different $(\mathrm{P}$-value $=0.464)$. Benson et al. (2014), found significant difference between adult and pediatric MS patients with more polysymptomatic presentation in pediatric cases. Other study postulated that children younger than 11 years were more likely to manifest with polyfocal features (49\%) compared with $37 \%$ of patients aged 14-16 years (Huppke et al., 2014). Most of pediatric patients in our study aged above 11 years.

Regarding type of presenting symptoms, our study demonstrated that no significant difference between adult and pediatric groups with predominance of optic, sensory and motor symptoms in both groups. Nobody presented with encephalopathy whereas seizures found in one pediatric patient (6.7\%). Two adult (13.3\%) and one pediatric (6.7\%) patients presented with isolated transverse myelitis.

All pediatric patients in our study was having initial course of relapsing remitting type whereas $13.3 \%$ of them developed secondary progressive course. No body have primary progressive course in pediatric group. About $6.7 \%$ of adult group have primary progressive course, $20 \%$ have secondary progressive and $73.3 \%$ are still having relapsing remitting course. There was no statistical significant difference between both groups as regard the course of the disease $(\mathrm{P}$-value $=0.651)$.

There was no significant difference between both groups in our study regarding EDSS scoring in with mean EDSS score of 3.37 and median of 3.25 for adults and mean of 2.4 and median of 1.5 for pediatric patients. Twenty percent of pediatric patients were having impaired ambulation (EDSS $\geq 4.5$ ) in comparison with $26.7 \%$ of adult patients. These findings are in agreement with Benson et al. (2014), which found no significant difference between adult and pediatric patients regarding EDSS in 6 years follow up study. 
Statistical analysis of distribution of MS lesions of the brain and spinal cord in this study, showed no significant difference between adult and pediatric patients. Infratentorial lesions were slightly more in pediatric cases whereas spinal cord lesions were slightly more in adult cases. The mean number of T2 lesions in brain MRI in our study was slightly more in pediatric patients than adults with statistical insignificant difference (12.53 in adult group versus 18 in pediatric group).

In a study of Chabaset al. (2008), pediatric MS patients had fewer brain MRI T2-bright foci and more frequent large MS lesions than with MS adults patients. However, recent studies show that onset in children with MS may have a higher lesion burden on their initial brain MRI scan than adults, especially those located in cerebellum and brainstem (Waubant\&Chabas, 2009). Quantitative analysis of T2 lesion volumes in study of Ghassemi et al. (2008), in patients with paediatric-onset or adult-onset multiple sclerosis, who were imaged early in the disease and matched for disease duration, showed very similar T2 lesion volumes.

Table 1:-

Table Summary of 2012 International Pediatric Multiple Sclerosis Study Group definitions for pediatric multiple sclerosis (MS) and immune-mediated CNS demyelinating disorders ${ }^{1}$

Pediatric clinically isolated syndrome (CIS) (all are required)

A clinical CNS event with presumed inflammatory demyelinating cause.

Absence of a clinical history of CNS demyelinating disease (if any, see pediatric MS).

No encephalopathy except as readily explained by fever.

Criteria for MS diagnosis on baseline MRI are not met.

Pediatric acute disseminated encephalomyelitis (ADEM) (all are required)

A first polyfocal, clinical CNS event with presumed inflammatory demyelinating cause.

An encephalopathy that cannot be explained by fever.

No new clinical or MRI findings 3 months or more after onset.

Brain MRI is abnormal during the acute ( 3 months) phase with typically diffuse, poorly demarcated large lesions involving predominantly the cerebral white matter.

Pediatric MS (any of the following)

Two or more CIS separated by more than 30 days involving more than one area of CNS.

One CIS associated with MRI findings consistent with criteria of dissemination in space (DIS) and in which a follow-up MRI shows at least one new lesion consistent with dissemination in time (DIT) criteria.

One ADEM attack followed by $1 \mathrm{CIS} 3$ or more months after symptom onset that is associated with new MRI findings consistent with criteria for DIS.

A CIS whose MRI findings are consistent with criteria for DIS and DIT lat least 1 T2 lesion in at least 2 of 4 areas: spinal cord, infratentorial, juxtacortical, and periventricular [DIS] associated with a simultaneous presence of asymptomatic gadolinium-enhancing and nonenhancing lesions [DIT] if the patient is $\geq 12$ years old] (revision proposed). 
Table 2:-

\begin{tabular}{|l|l|l|l|}
\hline Category & Adult & pediatric & P-value \\
\hline $\begin{array}{l}\text { Age } \\
(\text { Mean } \pm \text { SD) }\end{array}$ & $35.7 \pm 7.2$ & $18.4 \pm 4.5$ & \\
\hline $\begin{array}{l}\text { Gender (No, \%) - male } \\
- \text { female }\end{array}$ & $7(46.7) 8(53.3)$ & $6(40) 9(60)$ & 0.713 \\
\hline
\end{tabular}

Table 3:-

\begin{tabular}{|c|c|c|c|}
\hline & Adult & Pediatric & P-value \\
\hline $\begin{array}{l}\text { Age at 1stattack } \\
(\text { Mean } \pm \text { SD) }\end{array}$ & $29.5 \pm 5.54$ & $14.3 \pm 2.92$ & \\
\hline $\begin{array}{l}\text { Duration (weeks) } \\
(\text { Mean } \pm \text { SD) (Median, IQR) }\end{array}$ & $7 \pm 2.458(5.5-8)$ & $\begin{array}{l}6.47 \pm 3.235(4- \\
8.5)\end{array}$ & 0.619 \\
\hline $\begin{array}{l}\text { No of symptoms } \\
\text { (No \& \%) -monosymptomatic } \\
\text {-polysymptomatic }\end{array}$ & $8(53.3) 7(46.7)$ & $6(40) 9(60)$ & 0.464 \\
\hline $\begin{array}{l}\text { Improvement } \\
\text { (No \& \%) -complete -partial - } \\
\text { none }\end{array}$ & 7 (46.7 ) 7 (46.7) 1 (6.7) & $9(60) 6(40) 0(0)$ & 0.715 \\
\hline $\begin{array}{l}\text { Time between 1st, 2nd } \\
\text { attack (months)* (Mean } \pm \\
\text { SD) } \\
(\text { Median, IQR) }\end{array}$ & $20.68 \pm 14.4618(7.5-36)$ & $\begin{array}{l}8.8 \pm \\
6(4.75-12)\end{array}$ & 0.006 \\
\hline
\end{tabular}

Table 4:-

\begin{tabular}{|c|c|c|c|}
\hline Sympto m & Adult & Pediatric & P-value \\
\hline Motor & $5(33.3 \%)$ & $7(46.7 \%)$ & 0.71 \\
\hline Sensory & $6(40 \%)$ & $6(40 \%)$ & 1 \\
\hline Autonomic & $1(6.7 \%)$ & $1(6.7 \%)$ & 1 \\
\hline Optic & $8(53.3 \%)$ & $7(46.7 \%)$ & 0.715 \\
\hline Brainstem symptoms & $3(20 \%)$ & $3(20 \%)$ & 1 \\
\hline Cerebel lar & $1(6.7 \%)$ & $3(20 \%)$ & 0.598 \\
\hline mental & $1(6.7 \%)$ & $2(13.3 \%)$ & 1 \\
\hline seizures & $0(0 \%)$ & $1(6.7 \%)$ & 1 \\
\hline Transverse myelitis & $2(13.3 \%)$ & $1(6.7 \%)$ & 1 \\
\hline
\end{tabular}

Table 5:-

\begin{tabular}{|c|c|c|c|}
\hline & Adult & Pediatric & P-value \\
\hline $\begin{array}{l}\text { EDSS score } \\
(\text { Mean } \pm \text { SD) (Median, } \\
\text { IQR) }\end{array}$ & $\begin{array}{lcl}3.37 & \pm & 1.88 \\
3.25 & (1.37-4.1) & \end{array}$ & $2.4 \pm 2.441 .5(1-3)$ & 0.091 \\
\hline $\begin{array}{l}\text { Disability level } \\
\text {-Low disability (No \& \%) } \\
(\text { EDSS <4.5) } \\
\text {-High disability (No \& \%) } \\
(\text { EDSS } \geq 4.5)\end{array}$ & $\begin{array}{l}11(73.3) \\
4(26.7)\end{array}$ & $\begin{array}{l}12(80) \\
3(20)\end{array}$ & 1 \\
\hline
\end{tabular}

Table 6:-

\begin{tabular}{|c|c|c|c|c|c|c|}
\hline \multirow[t]{2}{*}{ Category } & \multicolumn{3}{|l|}{ Adult } & \multicolumn{3}{|l|}{ Pediatric } \\
\hline & $\mathrm{B}$ & $\mathrm{CI}$ & $\mathrm{P}$ & $\mathrm{B}$ & $\mathrm{CI}$ & $\mathrm{P}$ \\
\hline Age & 0.105 & $-0.036-0.249$ & 0.133 & 0.111 & $-0.207-0.130$ & 0.463 \\
\hline $\begin{array}{l}\text { Gender } \\
\text {-female -male }\end{array}$ & $\begin{array}{ll}\mathrm{RC} & - \\
0.688 & \end{array}$ & $\begin{array}{l}\mathrm{RC} \\
-2.835-1.460\end{array}$ & $\begin{array}{l}\mathrm{RC} \\
0.501\end{array}$ & $\begin{array}{ll}\mathrm{RC} & - \\
0.389 & \end{array}$ & $\begin{array}{l}\mathrm{RC} \\
-3.267-2.489\end{array}$ & 0.775 \\
\hline Age of onset & -0.047 & $-0.249-0.469$ & 0.626 & -0.063 & $-0.563-0.437$ & 0.790 \\
\hline
\end{tabular}




\begin{tabular}{|l|l|l|l|l|l|l|}
\hline Disease duration & 0.261 & $0.116-0.405$ & 0.002 & 0.219 & $-0.166-0.604$ & 0.241 \\
\hline Relapse rate presenting & -1.343 & $-2.877-0.190$ & 0.081 & 0.594 & $-2.217-3.405$ & 0.656 \\
\hline $\begin{array}{l}\text { No of } \\
\text { symptoms } \\
\text {-monosymptomatic } \\
\text { polysymptomatic }\end{array}$ & 0.821 & $-2.952-1.309$ & $\mathrm{RC}$ & $\mathrm{RC}$ & $\mathrm{RC}$ & 0.854 \\
\hline $\begin{array}{l}\text { Improvement from 1st } \\
\text { attack }\end{array}$ & $\mathrm{RC}$ & $\mathrm{RC}$ & 0.250 & $-2.634-3.134$ & \\
-complete -incomplet & 1.500 & $-0.270-3.270$ & 0.090 & 2.944 & $0.659-5.230$ & \\
\hline $\begin{array}{l}\text { Disease course } \\
\text {-RRMS -SPMS }\end{array}$ & $\mathrm{RC}$ & $\mathrm{RC}$ & $\mathrm{RC}$ & & \\
\hline
\end{tabular}

Table 7:-

\begin{tabular}{|c|c|c|c|c|}
\hline Location & Adult & Pediatric & All cases & P-value \\
\hline Periventricular & $15(100 \%)$ & $15(100 \%)$ & $30(100 \%)$ & 1 \\
\hline Juxtacortical & $15(100 \%)$ & $14(93.3 \%)$ & $29(96.7 \%)$ & 1 \\
\hline Cortical & $2(13.3 \%)$ & $3(20 \%)$ & $5(16.7 \%)$ & 1 \\
\hline Corpus callosum & $3(20 \%)$ & $9(60 \%)$ & $12(40 \%)$ & 0.06 \\
\hline Cerebellum & $2(13.3 \%)$ & $6(40 \%)$ & $8(26.7 \%)$ & 0.215 \\
\hline Brainstem & $3(20 \%)$ & $5(33.3 \%)$ & $8(26.7 \%)$ & 0.682 \\
\hline Spinal cord & $8(53.3 \%)$ & $5(33.3 \%)$ & $13(43.3 \%)$ & 0.269 \\
\hline
\end{tabular}

\section{References:-}

1. Benson, L, Healy B. C., Gorman M. P., Baruch, N. F., Gholipour, T., Musallam, A., \& Chitnis, T (2014). Elevated relapse rates in pediatric compared to adult MS persist for at least 6 years. Mult Scler Relat Disord 3(2), 186-193

2. Chabas D, Castillo-Trivino, T., Mowry, E. M., Strober, J. B., Glenn, O. A., \& waubant, E. (2008). Vanishing MS T2-bright lesions before puberty: a distinct MRI phenotype? Neurology 71 (14). 1090-1093.

3. Chong, H., Li, P., \& Benjamin, O. (2007). Pediatric multiple sclerosis is similar to adult-onset form in Asia. Neurology Asia, 12, 37-40.

4. EKMEKCI, O., YUCEYAR, N., \& SAGDUYU, A. K. (2012). Clinical features and Course in Pediatric Onset Multiple Sclerosis. Journal of Neurological Sciences, 29(4)

5. Ferreira, M. L., Machado, M. I., Dantas, M. J., Moreira, A. J., \& Souza, A. M. (2008). Pediatric multiple sclerosis: analysis of clinical and epidemiological aspects according to National MS Society Consensus 2007. Arq Neuropsiquiatr, 66(3B), 665-670.

6. Ghassemi, R., Antel, S. B., Narayanan, S., Francis, S. J., Bar-Or, A., Sadovnick, A. D., . . Canadian pediatric Demyelinating Disease Study, G. (2008). Lesion distribution in children with clinically isolated syndromes. Ann Neurol, 63 (3), 401-405.

7. Huppke, B., Ellenberger, D., Rosewich, H., friede, T., Gartner, J., \& Huppke, P. (2014). Clinical presentation of pediatric multiple sclerosis before puberty. Eur J Neurol, 21 (3), 441-446.

8. Inaloo, S., \& Haghbin, S. (2013). Multiple sclerosis in children. Iran J child Neurol, 7 (2), 1-10

9. Renoux, C., Vukusic, S., Mikaeloff, Y., Edan, G., Clanet, M., Dubois, B., . . . Adult Neurology Departments, K. S. G. (2007). Natural

10. history of multiple sclerosis with childhood onset. N Engl J Med, 356(25), 2603- 2613.

11. Tullman, M. J. (2013). Overview of the epidemiology, diagnosis, and disease progression associated with multiple sclerosis. Am J Manag Care, 19 (2 Suppl), S15-20.

12. Waubant, E., \& Chabas, D. (2009). Pediatric multiple sclerosis. Curr Treat Options Neurol, 11(3), 203-210

13. Weiner, H. L. (2008). A shift from adaptive to innate immunity: a potential mechanism of disease progression in multiple sclerosis. Neurol, 255 Suppl 1,3-11. 